\title{
From the Editors
}

We are very pleased to present this issue of the Canadian Journal of Children's Rights commemorating the 40th anniversary of the Canadian Human Rights Act and the 35th anniversary of the Canadian Charter of Rights and Freedoms. The theme of this issue, "children's rights as human rights," asks readers to consider whether it is possible, or even acceptable, to discuss children's rights as separate from human rights. While it may seem to be an innocuous question at first glance, the distinction in viewing children as human beings is quite profound. As fully human beings, rather than human 'becomings' or partially cultural, children gain full dignity as rights-holders when they are viewed in this way. This message of respect and dignity for children as full members of society reverberates throughout all of the submissions in this issue; that is, children and adults are part of a shared humanity with rights to protection, provision and participation in their social, cultural and political lives. The contributors to this issue -scholars, advocates, legal experts, and young people -- remind us of the importance of the relationality of rights that implicates each of us in ensuring that the rights of children are respected and fulfilled. This is partly accomplished by listening to what children and young people have to say about matters that affect their lives, and acting on what they say through adult leadership. It is through an understanding of the relationality of rights that there can be no question that children's rights are human rights.

We include a number of young people's perspectives that illuminate the complexity of the question of children's rights as human rights. Clive Linklater, writing about his elementary and secondary education at the Couchiching residential school in Ontario and then the Lebret residential school in Saskatchewan, describes for readers what it was like for him living through the misery of residential schooling. We are honoured to have his first-hand account of his experiences in this issue.

Samantha Crowe's poem Seven offers readers a powerful account of what it is like to live as a child and grow up through young adulthood in a context impacted by the intergenerational effects of systemic racialized, gendered, sexualized and classed colonialism. We are grateful to Samantha for allowing us to include Seven in this issue for our readership. 
Bernadette Perron and Élina Perron provide us with their reflections on the UN International Day of the Girl and the denunciation of violence and other injustices suffered by girls in Canada and globally. They ask important questions regarding how to achieve gender equality and freedom from violence for girls through affirmation of children's rights. Carine Plamondon follows with her essay on the legal context found in different provinces and territories regarding child protection in Canada. She demonstrates how legal decisions vary from vague dispositions to more stringent measures that impact the cultural identity of Indigenous children.

In the open section of the issue, children's advocates offer their insights and expertise regarding how to address some of the concerns raised by children and young people. In an interview conducted by Daniella Bendo, Landon Pearson speaks from her longstanding experience as a children's rights advocate to argue for the need for government to have capacity at the federal level to advocate for and with children and youth. She cites climate change and armed conflict as two pressing issues for children in contemporary contexts and notes the gaps in existing care systems as another issue of concern. Landon Pearson concludes that a carefully designed Office of the Federal Children's Commissioner could usefully address issues that arise for children and youth.

Kathy Vandergrift reflects on twenty-five years of advocating for the implementation of the Convention on the Rights of the Child in Canada. She argues that incorporating the Convention into Canadian law would improve not only the implementation of children's rights but it would have a positive impact on the ways governance works for young people in Canada.

Cindy Blackstock's article in this issue offers her views on improving the implementation of children's rights as well. She looks specifically at the United Nations Committee for the Rights of the Child and its efficacy in monitoring the implementation of the Convention by ratifying States Parties. Blackstock recommends reforms to the UN Committee in terms of membership and working methods in order to optimize and better promote children's rights, including child participation.

Three articles comprise the academic section of this issue. Mona Paré takes on the question of the inseparability of children's rights and human rights by discussing the importance to recognize children's rights as a legal concept that is part of wider international human rights law. Her examination of children's rights as legal norms 
points to Canadian practice as an example of some of the adverse effects on children when recognition of children's rights is lacking.

Kyriaki Patsianta offers an analysis of how the concept of the best interests of the child is conceptualized, evaluated and used in practice by the European Court of Human Rights in cases related to family relationships. She offers readers an analysis based on specific judgments of the European Court regarding equality between divorced parents in parental rights allocation to illustrate the complexity of the concept of the best interests of the child.

Brent Bezo's article in this section engages with the complexity of intergenerational trauma, historical trauma, and the impact on the rights of the child with reference to specific articles of the Convention. He offers a child rights perspective on intergenerational trauma noting that altered environments that are transmitted from generation to generation impact on children's right to environments free of maltreatment, abuse, poverty and their right to their own culture. Bezo points out the importance of multi-sectoral child-centred research initiatives and the recognition that intergenerational trauma is a children's rights issue.

We are grateful to all of the contributing authors for their insightful arguments, criticisms and creative work.

Our gratitude goes out to the J.W. McConnell Family Foundation for continued financial support of this Journal and to Patricia Moore of Carleton University's MacOdrum Library for her technical expertise with the open access system. We also wish to thank Sherry Prevenost for the photo that graces the cover of this issue. It is reproduced here with her permission (www.sherryprenevostphotography.com). Finally, the Journal benefits from an enthusiastic editorial board and dedicated reviewers who assist us in ensuring the production of a high quality Journal. Thank you to all. We hope you enjoy reading this issue!

Virginia Caputo and Landon Pearson 